This item was submitted to Loughborough's Research Repository by the author.

Items in Figshare are protected by copyright, with all rights reserved, unless otherwise indicated.

\title{
Gas build-up in a domestic property following releases of methane/hydrogen mixtures
}

PLEASE CITE THE PUBLISHED VERSION

http://dx.doi.org/10.1016/j.ijhydene.2009.01.060

\section{PUBLISHER}

(c) International Association for Hydrogen Energy. Published by Elsevier Ltd.

VERSION

AM (Accepted Manuscript)

LICENCE

CC BY-NC-ND 4.0

\section{REPOSITORY RECORD}

Lowesmith, Barbara J., Geoffrey Hankinson, C. Spataru, and M. Stobbart. 2014. "Gas Build-up in a Domestic Property Following Releases of Methane/hydrogen Mixtures". figshare. https://hdl.handle.net/2134/15088. 
This item was submitted to Loughborough's Institutional Repository (https://dspace.lboro.ac.uk/) by the author and is made available under the following Creative Commons Licence conditions.

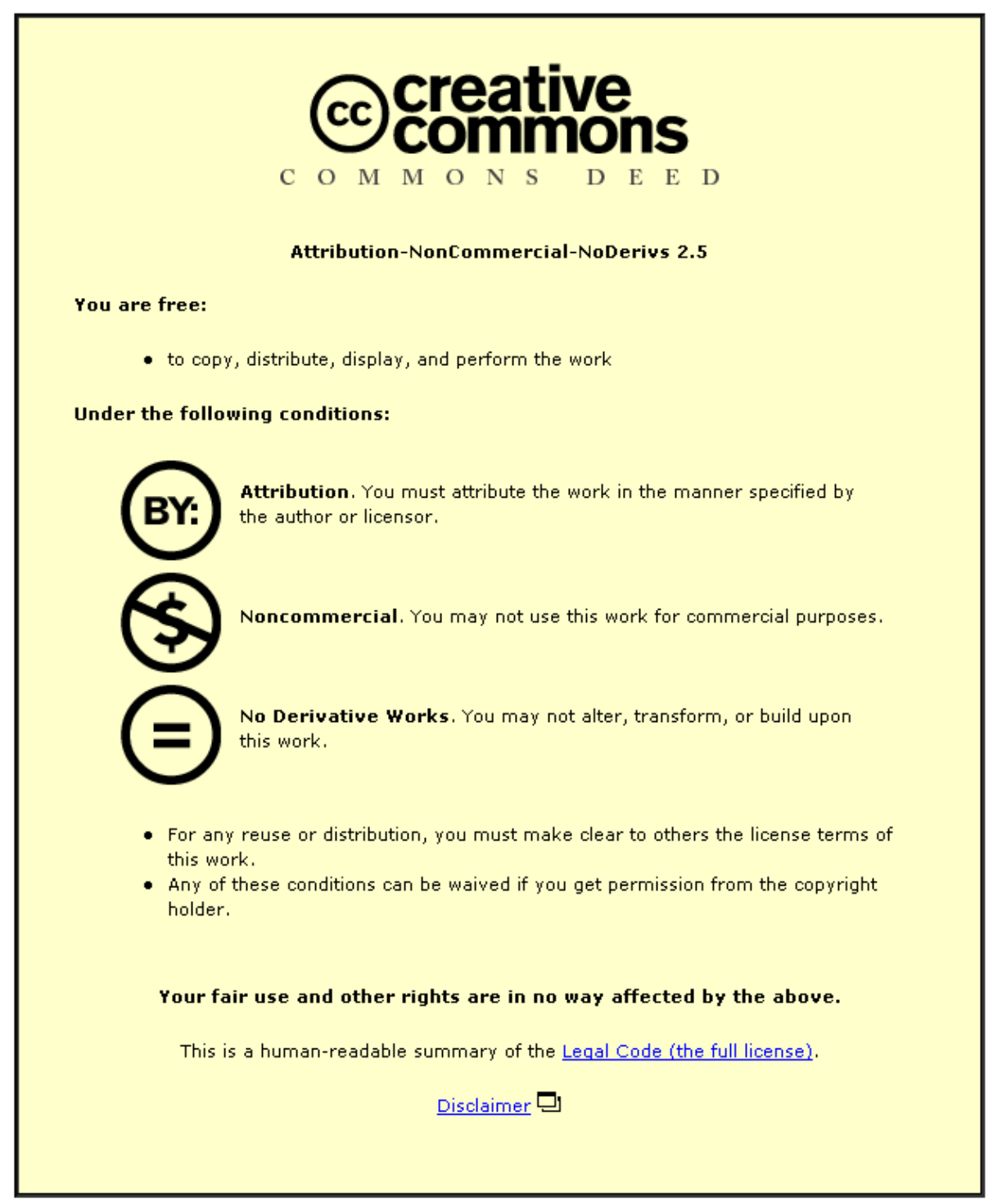

For the full text of this licence, please go to: http://creativecommons.org/licenses/by-nc-nd/2.5/ 


\title{
Gas Build-Up in a Domestic Property following Releases of
}

\section{Methane/Hydrogen Mixtures}

\author{
Lowesmith, B.J. ${ }^{\text {a,* }}$, Hankinson, G. ${ }^{\text {a }}$, Spataru, C. ${ }^{\text {a }}$, and Stobbart, M. ${ }^{\text {b }}$ \\ a Chemical Engineering Department, Loughborough University, UK \\ b Advantica Ltd, Spadeadam Test Site, Spadeadam, Cumbria, UK
}

Received

\begin{abstract}
The results of large scale experiments to study gas accumulation within a ventilated enclosure representing a domestic room are presented. Gas was released vertically upwards at a pressure typical of that experienced in a domestic environment from hole sizes representative of leaks and breaks in pipes. The released gas composition was either methane or a methane/hydrogen mixture containing up to $50 \%$ hydrogen. During the experiments, gas concentrations throughout the enclosure and the external wind conditions were monitored. A mathematical model has also been developed to describe the gas release as it mixes with air and forms a layer of gas/air mixture in the upper part of the enclosure. The model accounts for both wind and buoyancy driven ventilation, which arises as a result of the formation of the gas accumulation within the enclosure. The results show the importance of buoyancy driven ventilation on the steady state gas concentrations achieved.
\end{abstract}

\footnotetext{
* Corresponding author, Fax +44 1509 223923, email address: b.j.lowesmith@lboro.ac.uk
} 
Keywords: Methane and hydrogen gas build up, gas build up experiments, gas build up model

\section{Nomenclature}

$A=$ area of release, $\mathrm{m}^{2}$

$A_{v}=$ area of vent opening, $\mathrm{m}^{2}$

$B=$ coefficient of discharge of gas release $(=0.86)$

$c$ = gas concentration as a volume fraction in upper layer

$C_{d}=$ coefficient of discharge of the vents

$g$ = acceleration due to gravity, $\mathrm{m} \mathrm{s}^{-2}$

$g^{\prime}=$ reduced gravity, $\mathrm{m} \mathrm{s}^{-2}$, given by $g^{\prime}=\left(\frac{\rho_{\text {air }}-\rho_{l}}{\rho_{\text {air }}}\right) g$

$H=$ height of enclosure, $\mathrm{m}$

$H_{1}=$ height of upper vent above $h, \mathrm{~m}$

$h=$ height of interface between upper and lower layer, $\mathrm{m}$

$\dot{m}=$ mass release rate, $\mathrm{kg} \mathrm{s}^{-1}$

$P=$ gauge pressure immediately upstream of release, $\mathrm{Pa}$

$Q_{B}, Q_{W}=$ ventilation flow generated by buoyancy and wind respectively, $\mathrm{m}^{3} \mathrm{~s}^{-1}$

$Q_{i n}=$ flow rate of air entering enclosure, $\mathrm{m}^{3} \mathrm{~s}^{-1}$ 
$Q_{\text {out }}=$ flow rate of gas/air mixture leaving enclosure, $\mathrm{m}^{3} \mathrm{~s}^{-1}$

$Q_{j}=$ flow rate of gas/air mixture in jet entering upper layer, $\mathrm{m}^{3} \mathrm{~s}^{-1}$

$Q_{s}=$ flow rate of gas into enclosure, $\mathrm{m}^{3} \mathrm{~s}^{-1}$

$R=$ local jet radius, $\mathrm{m}$

$t=$ time, $\mathrm{s}$

$U_{j}=$ local mean jet velocity, $\mathrm{m} \mathrm{s}^{-1}$

$U_{W}=$ component of wind velocity normal to the ventilation opening, $\mathrm{m} \mathrm{s}^{-1}$

$V_{1}=$ volume of upper layer, $\mathrm{m}^{3}$

$Z=$ height above point of gas release, $\mathrm{m}$

$\alpha=$ entrainment constant

$\lambda=$ ratio of the transverse length scales of density and velocity

$\rho_{g}, \rho_{l}, \rho_{\text {air }}=$ density of gas, gas/air mixture in upper layer, air respectively, $\mathrm{kg} \mathrm{m}^{-3}$

\section{Background}

Hydrogen is seen as an important energy carrier for the future which offers carbon free emissions at the point of use. However, transition to the hydrogen economy is likely to be lengthy and will take considerable investment with major changes to the technologies required for the manufacture, transport and use of hydrogen. In order to facilitate the 
transition to the hydrogen economy, the European Commission funded project Naturalhy is studying the potential for the existing natural gas pipeline networks to transport hydrogen from manufacturing sites to hydrogen users. The hydrogen, introduced into the pipeline network, would mix with the natural gas. This mixture could then be used directly by consumers as a fuel within existing gas powered equipment, with the benefit of lower carbon emissions. In addition, hydrogen could be extracted from the mixture for use in hydrogen powered engines or for hydrogen fuel cell applications. Using the existing pipeline network to convey hydrogen in this way, would enable hydrogen production and hydrogen fuelled applications to become established prior to the development of a dedicated hydrogen transportation system, which would require considerable capital investment and time for construction.

However, the existing gas pipeline networks are designed, constructed and operated based on the premise that natural gas is the material to be conveyed. Hydrogen has different chemical and physical properties which may adversely affect the integrity or durability of the pipeline network, or which may increase the risk presented to the public. For these reasons, the Naturalhy project has been initiated to assess the feasibility and impact of introducing hydrogen into a natural gas pipeline system. Determining any change in risk to the public is a major part of this project. For example, although rare, escapes of gas from faulty appliances or joints in internal pipe work do occur and sometimes result in the formation of a flammable accumulation. Each year, a small number of such escapes result in an explosion with the potential to harm the occupants and cause damage to the building. The introduction of hydrogen into the supplied gas may increase the risk of such explosions due to the change in way in which the gas accumulation forms and/or due to the 
increased reactivity of hydrogen. In order to understand the nature of any accumulation of natural gas/hydrogen which may form and to identify the controlling parameters, a series of large scale experiments have been undertaken in which methane/hydrogen mixtures were released within a room-sized enclosure under conditions which are typical of a domestic environment. Assessment of the data enabled identification of the controlling parameters and aided the development and validation of a mathematical model.

\section{Introduction}

The concentration and extent of the flammable accumulation will affect the severity of the resulting explosion and hence it is important to understand the controlling parameters of gas build-up behaviour. For natural gas, the characteristics of gas escapes in the home are well understood. For example, gas accumulations will tend to form a layer of uniform concentration in that part of the room above the height of the release point. Factors which contribute to this behaviour are: the low momentum of gas release (due to the typical gas pressure being 20-30 mbar); the density of natural gas being less than that of air; and the generally low velocity of airflow (ventilation) within domestic buildings.

However, natural gas/hydrogen mixtures have a lower density than natural gas and this may give rise to different gas accumulation behaviour. Also, for a given supply pressure and leak size, the volume flow rate of natural gas/hydrogen will be greater than the equivalent leak involving methane. Hence, it might be expected that the resulting gas concentration will be higher. Furthermore, due to the wide flammability limits of the mixture, a larger flammable volume may result. In order to assess any change in gas 
accumulation behaviour, the large scale experiments reported here studied gas releases at pressures typical of that found in a domestic building from leak sizes typical of those that may occur, involving methane (representing natural gas) and methane/hydrogen mixtures. As a flammable concentration will be reached more readily if the escape results in an accumulation in only part of the room (a 'layer') this represents the more hazardous situation. Hence, the experimental programme was designed such that most tests involved a gas release which was vertically upwards from a location at half-height. Furthermore, the ventilation regime was such that air would enter the room at low level and gas mixture leave the room at high level. This situation promoted the formation of a 'layer' in the upper part of the room.

\section{Experimental details}

\subsection{Experimental Arrangement}

The experiments were conducted at the Advantica Limited test site at Spadeadam in the north of England. The test rig was designed to represent a typical domestic room and consequently measured $3 \mathrm{~m}$ by $3 \mathrm{~m}$ by $2.3 \mathrm{~m}$ high. Figure 1 shows a schematic of the test arrangement. In one wall of the test rig (front wall) a lightweight door (typical of that used inside a domestic property) was installed measuring $0.9 \mathrm{~m}$ by $2 \mathrm{~m}$ high. This was located within a typical door frame and a door jamb nailed to the doorframe to hold the door in place. The arrangement was therefore characteristic of the situation where the door opens into the room. The two side walls, each adjacent to the front wall, incorporated ventilation openings which could be adjusted in size and could provide a well-defined ventilation pattern to the enclosure. The upwind side wall (facing the wind) had an opening at low 
level, located $200 \mathrm{~mm}$ above the floor. The downwind side had an opening the same size at high level, 200mm below the ceiling. Each ventilation opening measured $1 \mathrm{~m}$ in the horizontal direction and was adjusted in size in the vertical direction. The back wall, floor and ceiling were plain and incorporated no fittings.

The gas used for the experiments was supplied in high pressure (20MPa) cylinders. Four different gases were used, methane and three mixtures of hydrogen and methane which contained nominally $10 \%, 20 \%$ and $50 \%$ by volume hydrogen respectively. Hereafter, these mixtures will be referred to as 90:10, 80:20 and 50:50 respectively. The pressure was reduced in stages and controlled to provide a fixed gauge pressure at the release point of either 20 or 30 mbar.

The leak was simulated by a hole of a pre-determined size (5 or $10 \mathrm{~mm}$ diameter) drilled into a fitting at the end of the gas supply pipe work. The release point was positioned close to the back wall of the test rig, in the centre of wall (horizontally). For most of the tests, the release point was positioned at a height of $1.1 \mathrm{~m}$ above the floor, but for 2 tests, it was located close to the floor. In all cases, the release was directed vertically upwards (see Table1).

\subsection{Scientific Measurements}

The gas release pressure and temperature were measured close to the release point. The gas release rate was then calculated using: 


$$
\dot{m}=B A \sqrt{\left(2 \rho_{g} P\right)}
$$

The gas concentration was measured during each experiment using twenty A02 CiTicel detectors which measure the oxygen content of the atmosphere from which the gas concentration was determined. At the beginning of each test, prior to activation of the gas release, the output signals of the oxygen cells were recorded (nominally $10 \mathrm{mV}$ ) and taken to be representative of the oxygen concentration in the atmosphere corresponding to $0 \%$ gas. During the gas release, the signal decreased, being linearly related to the concentration of gas. The error analysis concluded that the gas concentrations could be measured with an accuracy of $\pm 0.1 \%$. The oxygen cells were located throughout the enclosure at different horizontal and vertical positions to determine the nature of the gas/air mixtures formed during the tests.

The prevailing wind speed and direction was measured at a location approximately $60 \mathrm{~m}$ from the test rig. The wind speed was measured at heights above the ground of 3, 4.85, 8.4 and $10.75 \mathrm{~m}$.

\section{Test programme}

Table 1 summarises the test conditions for 8 tests. As can be seen, six tests considered a $10 \mathrm{~mm}$ diameter leak at nominally 0.3 Pa representing a break of typical internal pipe work. Two tests studied a $5 \mathrm{~mm}$ diameter leak at nominally 0.2 Pa representing smaller failures, such as, a leak from a joint or a faulty appliance. 


\section{Experimental Results}

In all cases, it was found that the gas concentrations measured at different locations within the enclosure but at the same height were the same, indicating that the gas accumulation was uniform in the horizontal plane and only varied with height above the floor. Consequently, in the results presented here, only the height of the sensor (oxygen cell) above the floor is given.

Figure 2 shows the results of the measurements of gas concentration made using the 20 oxygen cells located within the room during Test 6 . The time at which the gas release was initiated and terminated is shown. As can be seen, the gas concentrations increased with time until a steady state concentration was reached and prevailed until the gas release was terminated. It can also be seen that the gas concentrations were very low (less than $1 \%$ ) for all sensors located $1.1 \mathrm{~m}$ or lower above the floor. Similarly, all sensors located $1.6 \mathrm{~m}$ or higher gave similar results, indicating an accumulation between $1.6 \mathrm{~m}$ and the ceiling which had a uniform concentration throughout. In the zone between these two regions the concentration varied significantly with height.

Figure 3 shows the results of the same test presented as gas concentration with height within the room. To produce this plot, for selected times after the onset of the gas release, the measurements made at sensors at the same height within the enclosure were averaged. This clearly shows that the formation of a layer of essentially uniform concentration occurs at an early stage after onset of the gas release, and that thereafter, the gas concentration in this layer increases until the steady state concentration is reached. For this test, the 
selected steady state period was $1300-1750 \mathrm{~s}$ and the steady state gas concentration in the layer was $18.6 \%$.

After the gas release was terminated, the gas accumulation dispersed. Figure 4 shows the dispersal phase for Test 6 and was produced in a similar manner to Figure 3. It can be seen that, following termination of the gas release, the layer of uniform concentration was not maintained. High gas concentrations persisted for some time close to the ceiling but at lower heights, the concentrations were significantly lower and gas accumulation was quickly dispersed.

The formation of a layer of essentially uniform concentration and the absence of gas below the height of the release was observed in all of Tests 1 to 6 where the release was from a height of $1.1 \mathrm{~m}$ above the floor, although the level of gas concentration achieved at steady state and the rate of change of gas concentration during the build-up phase differed from test to test due to the different release conditions and prevailing wind conditions.

Figures 5 and 6 show the formation and dispersal of the gas accumulation during Test 8 , where the gas was released from close to the floor. In this Test, and in Test 7, the layer of uniform concentration extended almost down to the floor.

Table 2 summarises the height of the bottom of the layer (the interface) and the average gas concentration at steady state for all the tests. Also shown in the table are the calculated 
gas release rates, the measured wind speeds at $10.75 \mathrm{~m}$ above ground and the angle of incidence of the wind onto the inlet vent (all during the steady state period for each test).

\section{Mathematical model of gas build-up}

Due to the different wind conditions which prevailed over the test series and the different heights of the ventilation openings, it was not easy to compare directly the absolute concentration levels achieved during the tests. Such a comparison is best achieved with the use of a mathematical model.

Figure 7 shows, diagrammatically, the main elements of the model that has been developed. Gas was assumed to be released into the enclosure at a steady rate. The buildup of gas within the enclosure and the evolution of the upper buoyant layer was analyzed from onset of the release until steady state was achieved using a simple mathematical model.

It was assumed that prior to the release of gas the enclosure was filled with air and that air flowed through the enclosure as a result of wind generated ventilation. Following commencement of the release of gas (lighter than air) a buoyant jet was formed into which air was entrained resulting in the formation of an upper buoyant layer of gas/air mixture and a lower layer of air. Within the upper layer the concentration of gas was assumed to be uniform. These assumptions are based on the observations made during the experiments. It was assumed that no mixing occurred across the interface separating the upper lower layers, and that the only transfer taking place was by means of the jet. 
It was assumed that the wind driven ventilation flow entering the enclosure through the lower vent (and hence entering the lower layer) was augmented by buoyancy generated ventilation flow. It was also assumed that gas/air mixture at the concentration prevailing in the upper layer flowed out of the enclosure through the upper vent.

The objective of the analysis was to determine both the variation in the volume of the upper layer, $V_{1}$, (i.e. the change in position of the interface, $h$ ), and the build-up of gas in the upper layer, $c$, during the transient part of the release and also their steady state values.

Firstly, it was necessary to consider the evolution of the volume of the upper layer. Following Kaye and Hunt [1] the rate of change of the volume of the upper layer can be expressed as:

$\frac{d V_{1}}{d t}=Q_{j}-Q_{\text {out }}=Q_{j}-\left(Q_{\text {in }}+Q_{s}\right)$

Secondly, it was necessary to consider the build-up of gas in the upper layer. The rate of change of volume of gas in the upper layer can be expressed as: 
$\frac{d\left(V_{1} c\right)}{d t}=V_{1} \frac{d c}{d t}+c \frac{d V_{1}}{d t}=Q_{s}-c\left(Q_{i n}+Q_{s}\right)$

Substituting for $\frac{d V_{1}}{d t}$ from equation (2), gives:

$V_{1} \frac{d c}{d t}+c\left(Q_{j}-\left(Q_{i n}+Q_{s}\right)\right)=Q_{s}-c\left(Q_{i n}+Q_{s}\right)$

Therefore the rate of change of the concentration is given by:

$V_{1} \frac{d c}{d t}=Q_{s}-c Q_{j}$

To solve the pair of equations (2) and (4) numerically, it was necessary to establish relationships for the volume flow rate of ventilation air into the enclosure through the lower vent, $Q_{i n}$, and the volume flow rate of gas/air mixture from the jet into the upper layer, $Q_{j}$.

To determine $Q_{i n}$, the approach described in Warren and Webb [2] was followed in which:

$Q_{i n}=\sqrt{Q_{B}^{2}+Q_{W}^{2}}$ 
Considering the effective height of the upper buoyant layer as the vertical distance from the interface to the centre of the upper vent, $H_{1}$, then the ventilation flow generated by buoyancy can be expressed as:

$Q_{B}=\frac{C_{d} A_{v}}{\sqrt{2}} \sqrt{2 g^{\prime} H_{1}}$

A value of $C_{d}=0.61$ was used (Etheridge and Sandberg [3]). The ventilation flow generated by the wind can be expressed as:

$$
Q_{W}=\frac{C_{d} A_{v}}{\sqrt{2}} U_{W}
$$

To determine $Q_{j}$, the model for a buoyant jet of Lane-Serff et al [4] was adopted. The two main assumptions of this approach are the Boussinesq approximation (discussed in detail by Turner [5]) and relating entrainment into the jet as proportional to the local mean jet velocity. The constant of proportionality is called the entrainment constant, $\alpha$.

An entrainment constant was first used explicitly by Morton, Taylor and Turner [6]. Numerous experimental studies have provided values of the entrainment constant such as 
Rouse, Yih and Humphreys [7], Chen and Rodi [8]. A value of $\alpha=0.05$ taken from Rodi [9] was used in this analysis.

Following Lane-Serff et al [4], conservation equations for mass, momentum and buoyancy were written as:

$\frac{d\left(U_{j} R^{2}\right)}{d Z}=2 R \alpha U_{j}$

$\frac{d\left(U_{j}{ }^{2} R^{2}\right)}{d Z}=g^{\prime}(\lambda R)^{2}$

$\frac{d\left(g^{\prime} U_{j} R^{2}\right)}{d Z}=0$

Following Lane-Serff et al [4], a value of $\lambda$ of 1.1 was adopted.

Equations (8a) to (8c) were non-dimensionalised and transformed as described by LaneSerff et al [4] and integrated at each time step during the solution of equations (2) and (4) to determine the mean jet velocity, $U_{j}$, and the jet radius, $R$, at the height at which the jet 
entered the upper buoyant layer. This enabled the flow rate of gas/air mixture into the upper layer, $Q_{j}$, to be calculated.

\section{Results from the model}

Figure 8 shows a comparison of the model predictions with experimental measurements of the build-up of gas within the upper layer of the enclosure during Tests 6 and 8 . The predicted steady state level of the interface between the upper and lower layers was $1.28 \mathrm{~m}$ and $0.21 \mathrm{~m}$ for Tests 6 and 8, respectively. These values compare with experimental measurements of $1.3 \mathrm{~m}$ and $0.2 \mathrm{~m}$, for Tests 6 and 8 , respectively.

Figure 9 shows the steady state concentration predicted by the model compared with the steady state concentration measured during all the experiments.

Figure 10 shows the effect of varying the percentage of hydrogen in the released methane/hydrogen mixture on the gas accumulation in the upper layer in the enclosure and on the height of the interface between the upper and lower layers predicted by the model.

\section{Discussion}

The predictions of the model showed good agreement with the experimental data and demonstrate that the model performs well for the upward directed relatively low 
momentum releases of buoyant gas into the ventilated enclosure under consideration. Consequently, the model was used to investigate the influence on the gas accumulation of changes in different parameters. The Naturalhy project is concerned with the introduction of hydrogen into existing natural gas infrastructures. Therefore, it is of interest to understand the difference in behaviour of releases of different composition under identical release conditions.

The predictions presented in Figure 10 shows the effect of varying the percentage of hydrogen in the released methane/hydrogen mixture on the gas accumulation in the upper layer in the enclosure and on the height of the interface between the upper and lower layers. As a consequence of raising the percentage of hydrogen, the volume flow rate of the gas released into the enclosure increased. This results in a rise in the gas concentration and an increase in the volume of the region in which the gas accumulates. However, the rise in hydrogen content of the released gas also leads to enhancing the buoyancy which in turn leads to an increase in the ventilation air flow. Consequently, the rise in concentration is not as great as might otherwise have been expected. Nevertheless, the concentrations are higher and, due to the wider flammable limits, the duration over which a flammable inventory is present will also be increased. Both these factors will need to be considered when assessing the change in risk presented to the domestic customer as a result of introducing hydrogen into the supplied gas. The experimental data and the mathematical model described herein will facilitate quantification of this change in risk. 


\section{Acknowledgements}

The authors would like to thank the European Commission for providing the financial support for this study as part of the Naturalhy project.

\section{References}

1. Kaye NB, Hunt GR. Time-dependent flows in an emptying filling box, J. Fluid Mech. 2004; 520: 135-156.

2. Warren PR, Webb BC. The relationship between tracer gas and pressurisation techniques in dwellings. Proc. 1st AIC Conf. "Instrumentation and Measurement Techniques”, Windsor, UK, 1980: 245-276.

3. Etheridge D, Sandberg M, Building Ventilation: Theory and Measurement, Wiley, Chichester, 1996.

4. Lane-Serff GF, Linden PF, Hillel M. Forced, angled plumes, Journal of Hazardous Materials, 1993; 33: 75-99.

5. Turner JS, Buoyancy effects in fluids. Cambridge University Press, London, 1973.

6. Morton BR, Taylor GI, Turner JS. Turbulent gravitational convection from maintained and instantaneous sources. Proc. R. Soc. London, 1956; A234: 1-23.

7. Rouse H, Yih CS, Humphreys HW. Gravitational convection from a boundary source, Tellus, 1952; 4: 201-210.

8. Chen CJ, Rodi W. Vertical turbulent buoyant jets: A review of experimental data, Pergamon Press, Oxford, 1980. 
9. Rodi W. Turbulent Buoyant Jets and Plumes, Pergamon Press, Oxford, 1982: p. 47.

Figure 1: Schematic of the test arrangement

Figure 2: Gas concentration with time during Test 6

Figure 3: Gas layer formation within the room during Test 6

Figure 4: Gas layer dispersal during Test 6

Figure 5: Gas layer formation within the room during Test 8

Figure 6: Gas layer dispersal during Test 8

Figure 7: Main elements of the model

Figure 8: Gas concentration with time, Tests 6 and 8

Figure 9: Steady state gas concentration for all tests

Figure 10: Steady state gas concentration and height of interface with amount of hydrogen in the released gas

Table 1: Summary of the experimental conditions

Table 2: Summary of the gas layer formed at steady state 

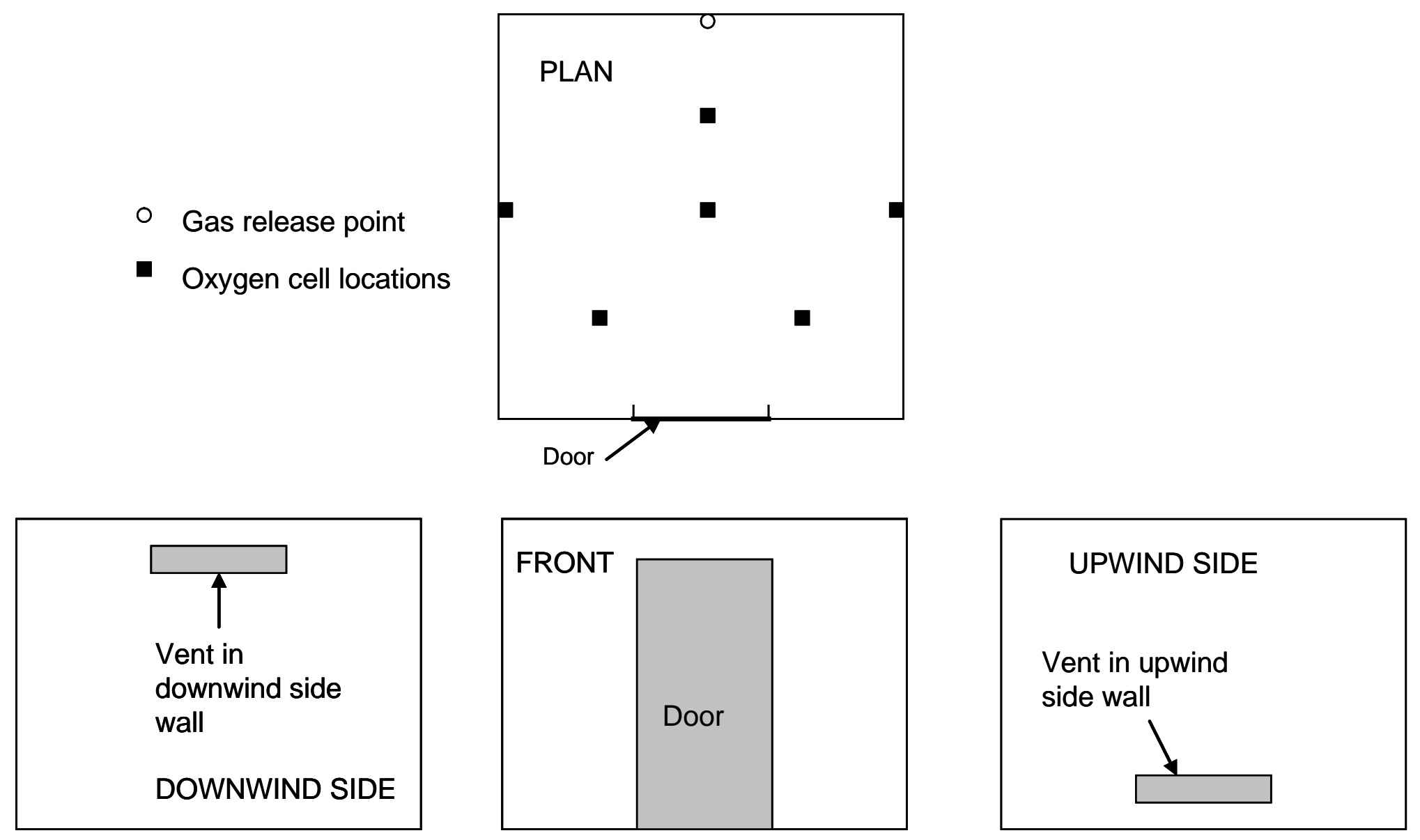

Figure 1. Schematic of the test arrangement 


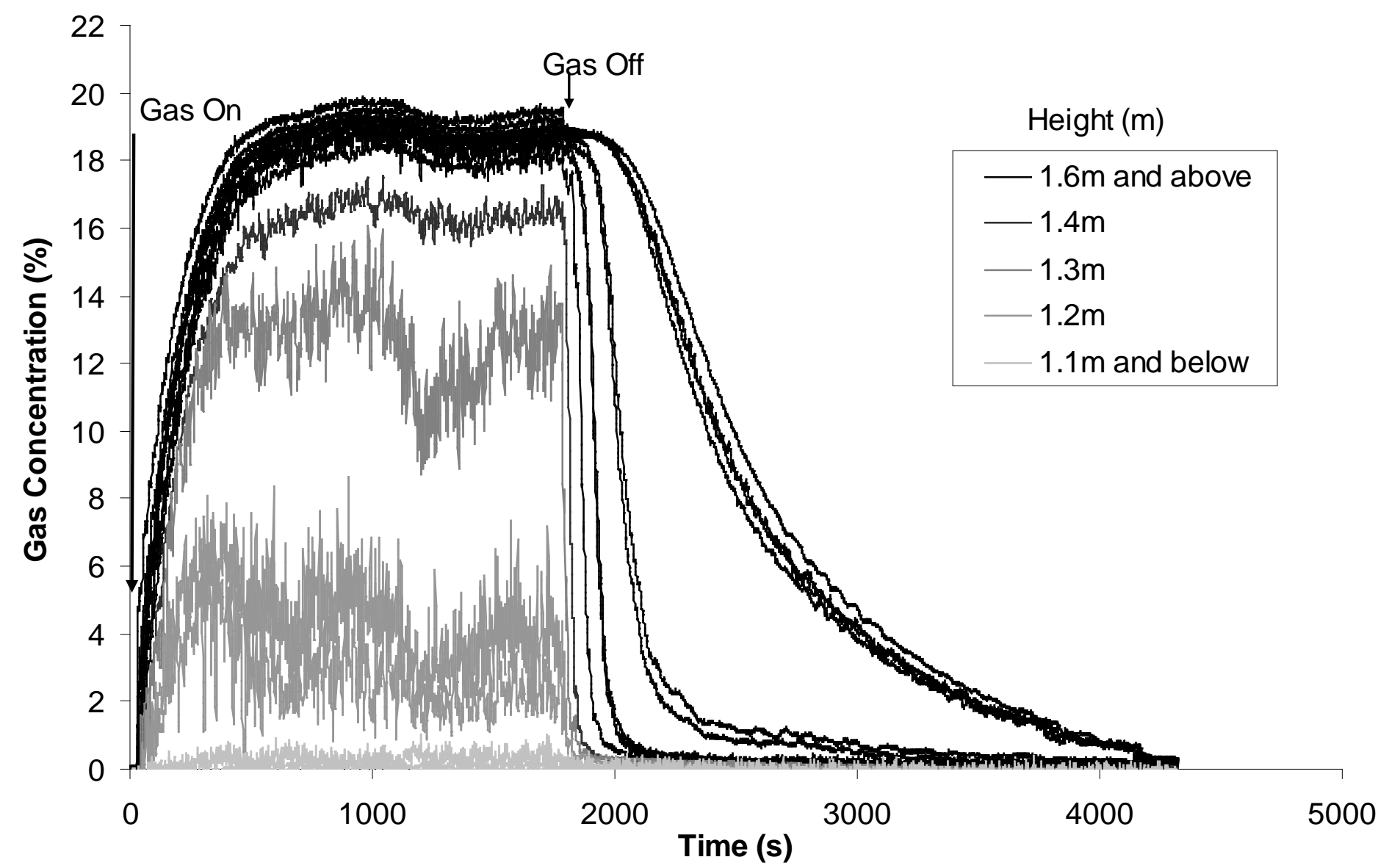

Figure 2. Gas concentration with time during Test 6 


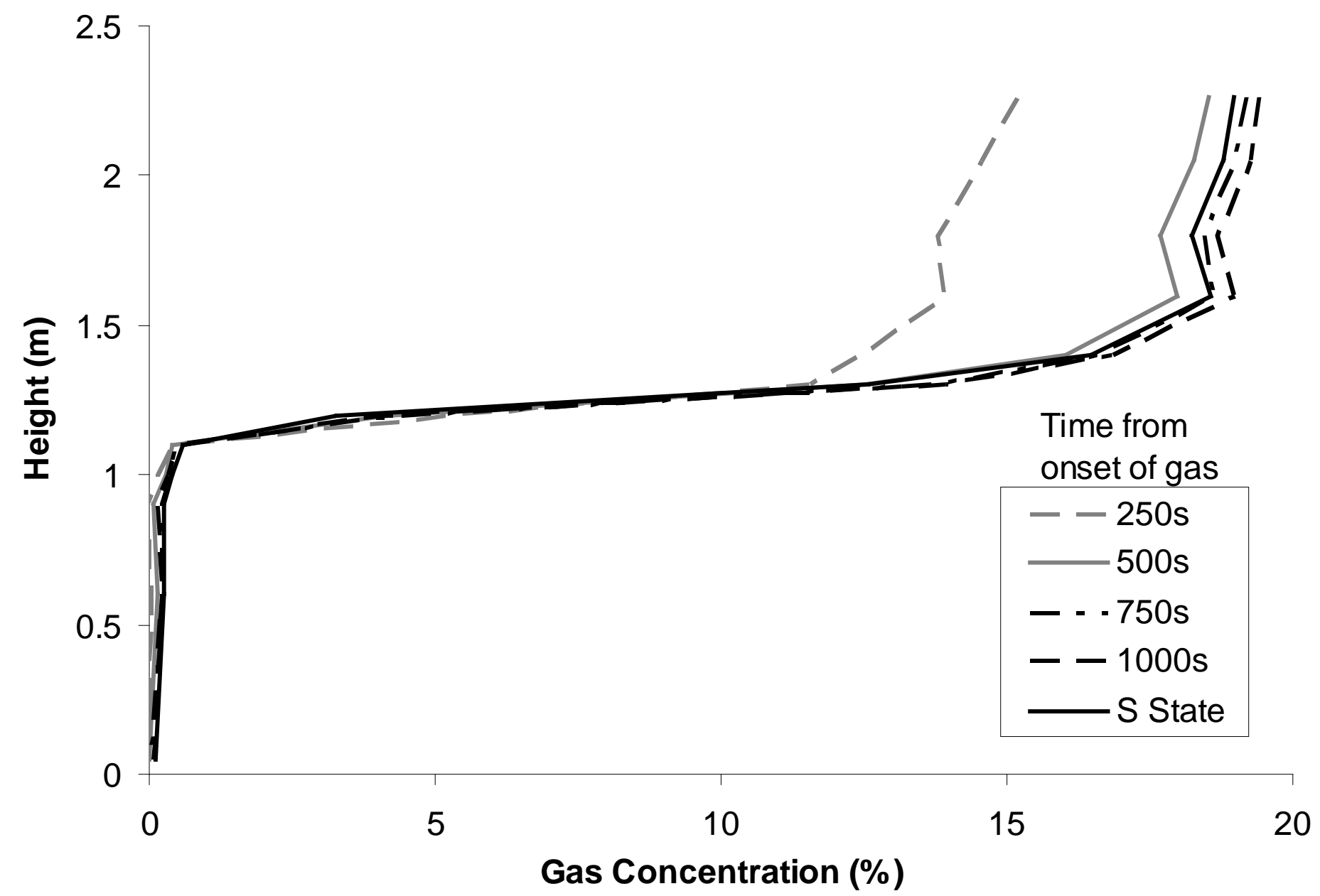

Figure 3. Gas layer formation within the room during Test 6 


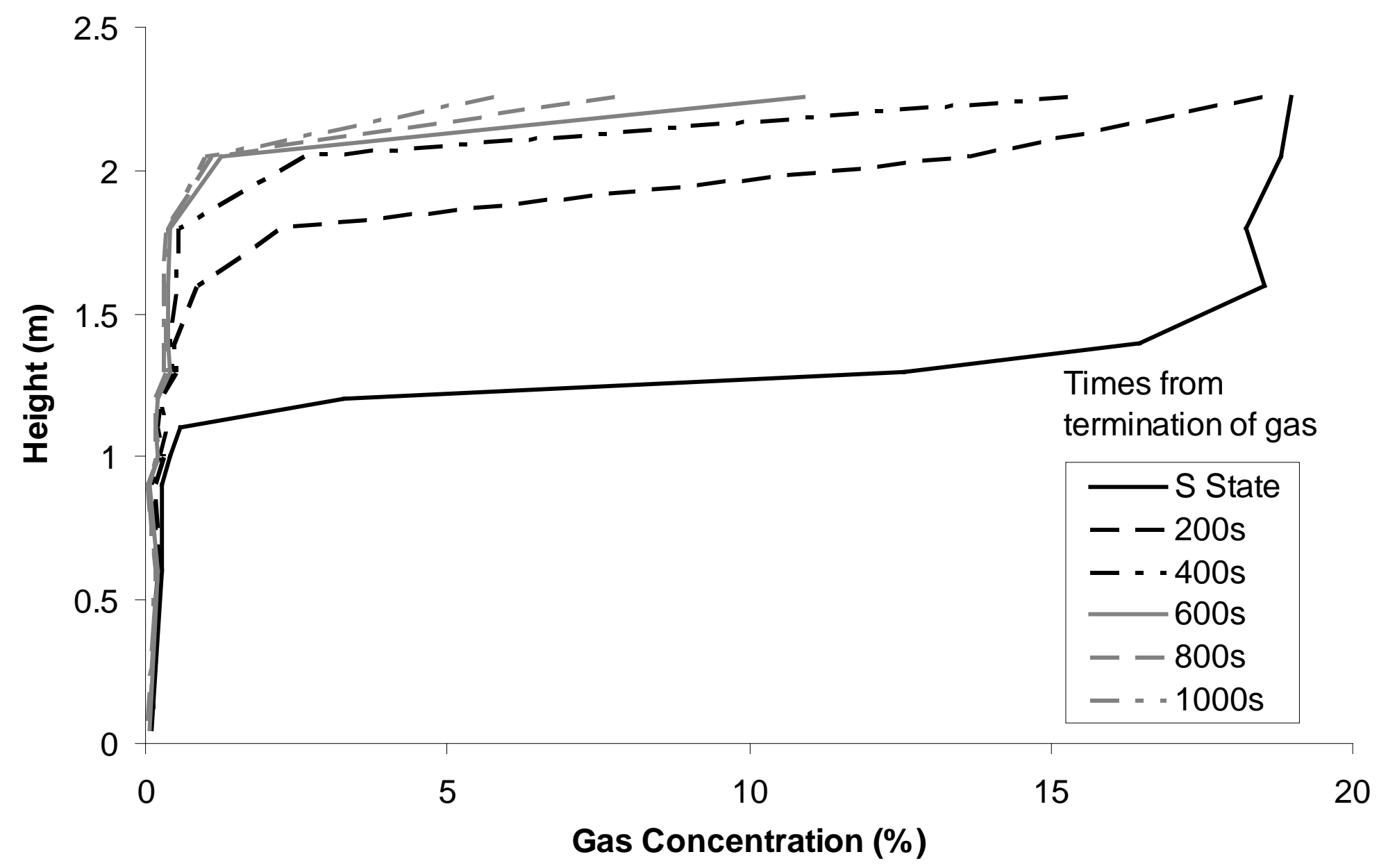

Figure 4. Gas layer dispersal during Test 6 


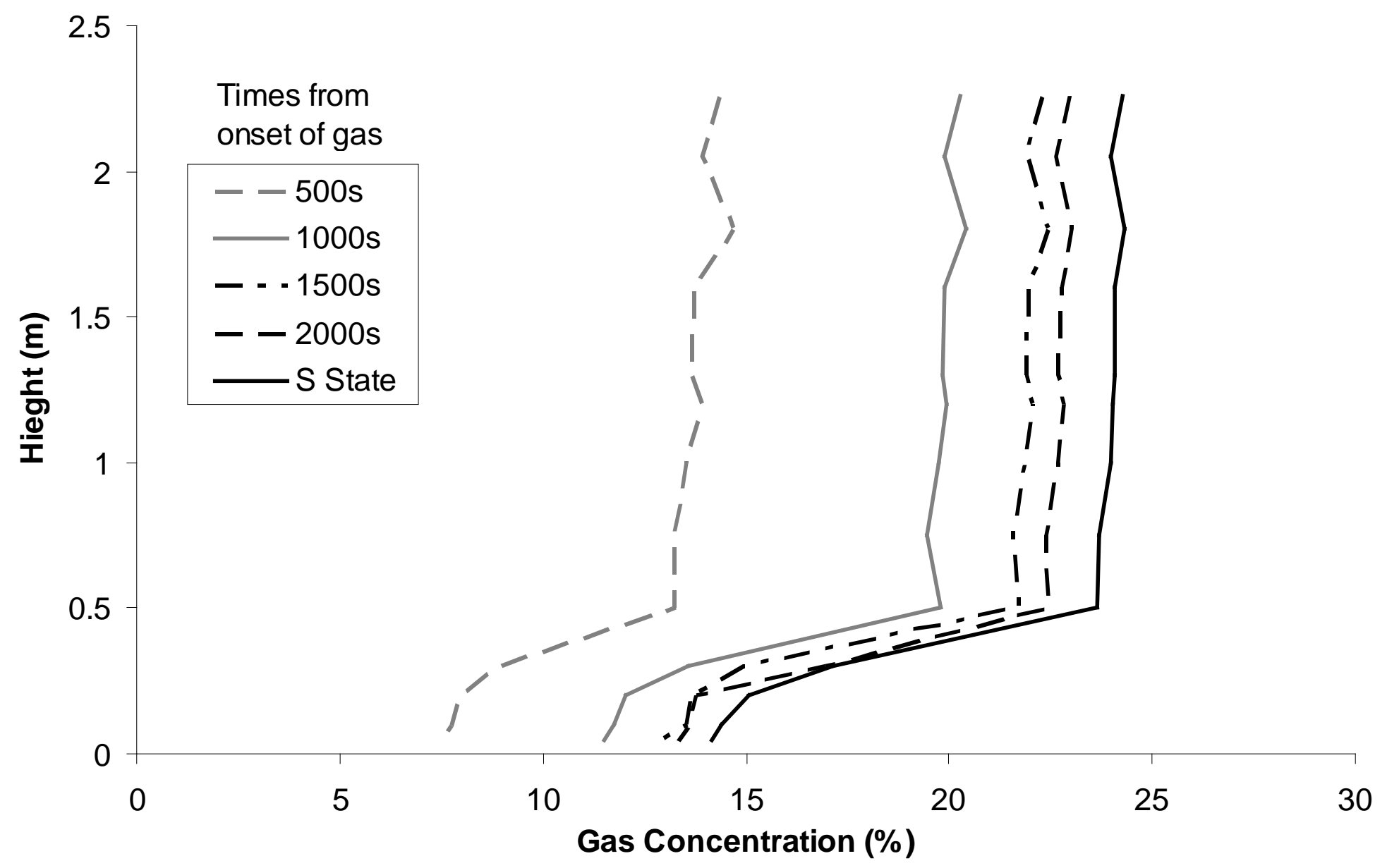

Figure 5. Gas layer formation within the room during Test 8 


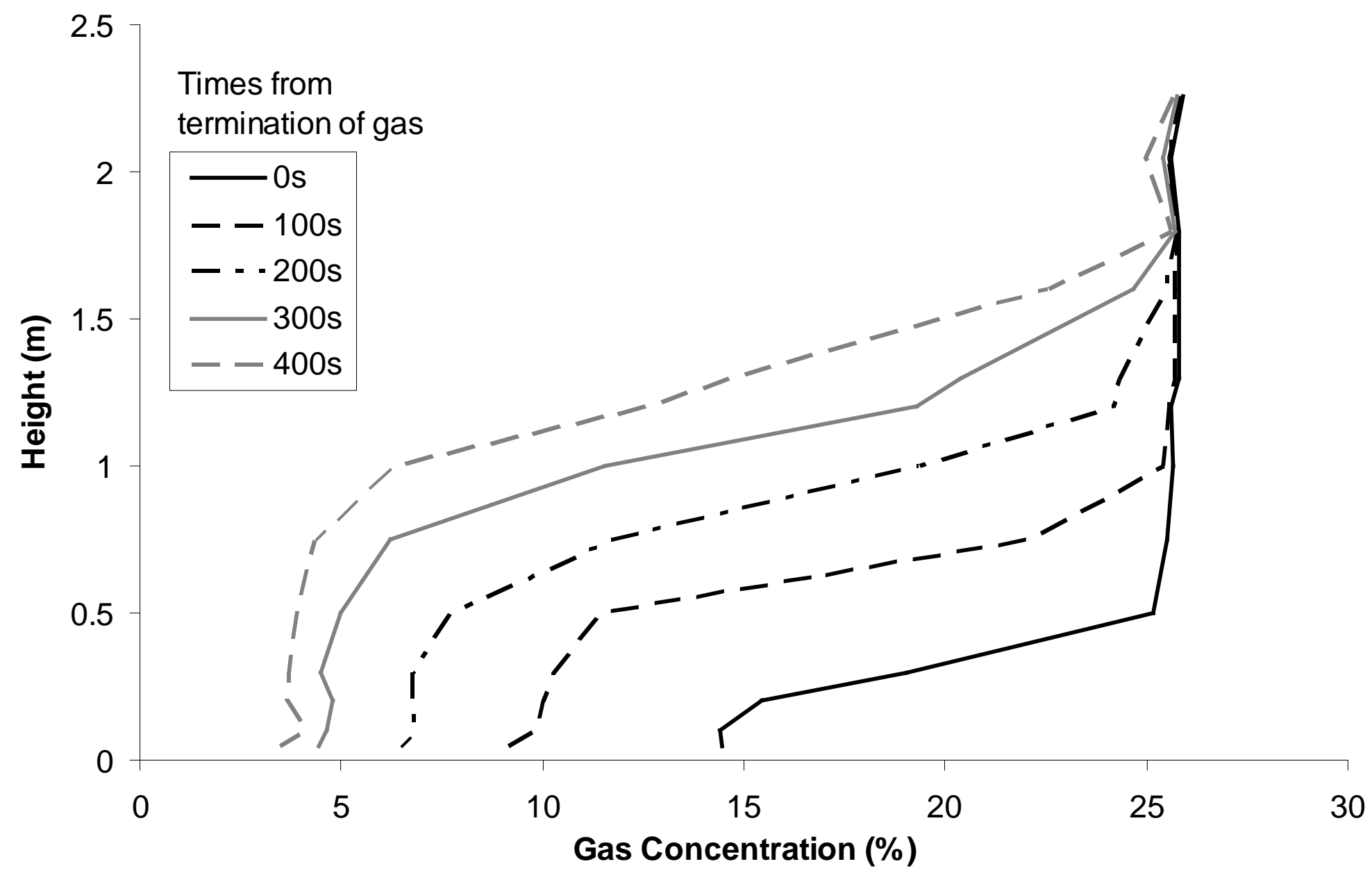

Figure 6. Gas layer dispersal during Test 8 


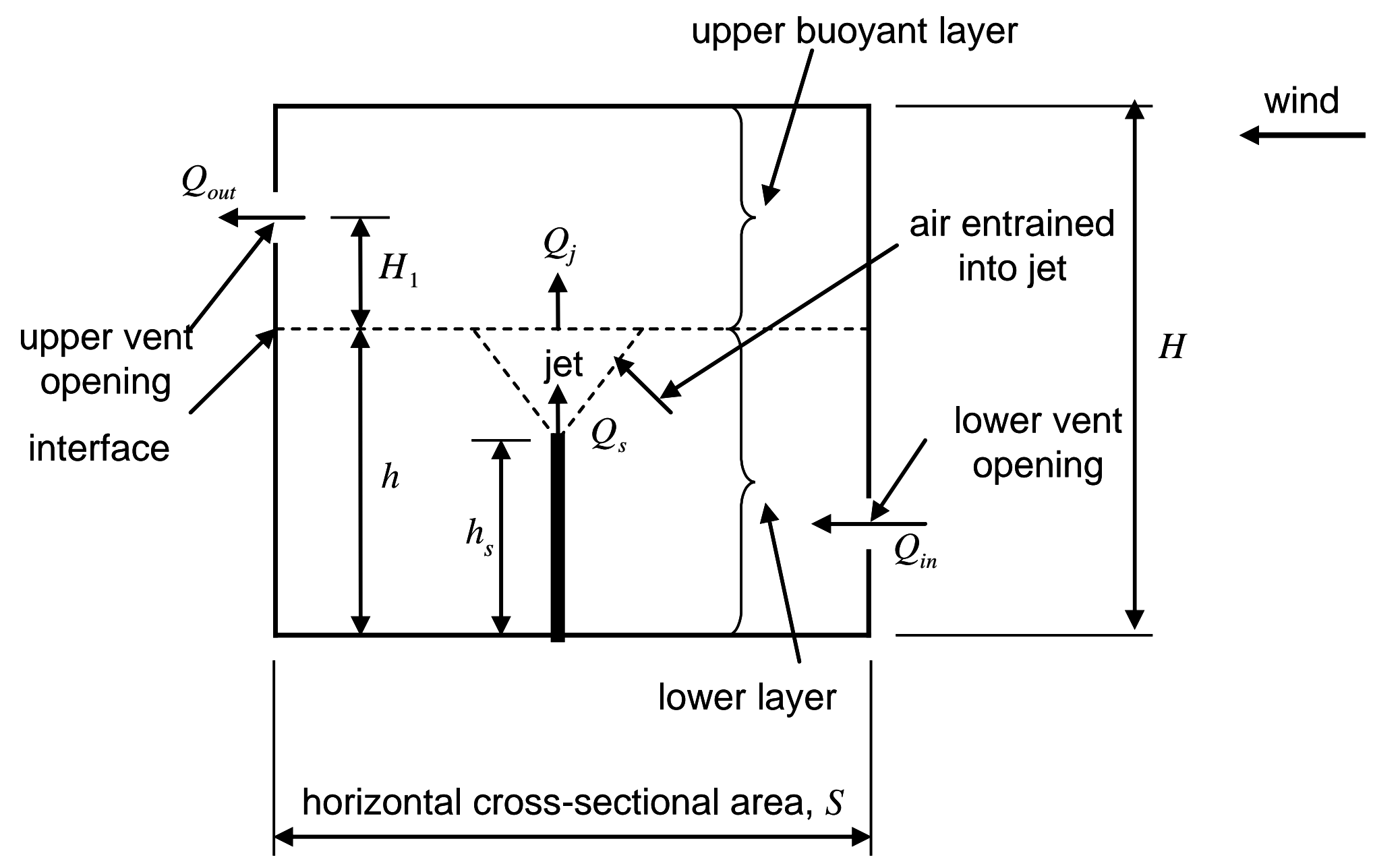

Figure 7. Main elements of the model 


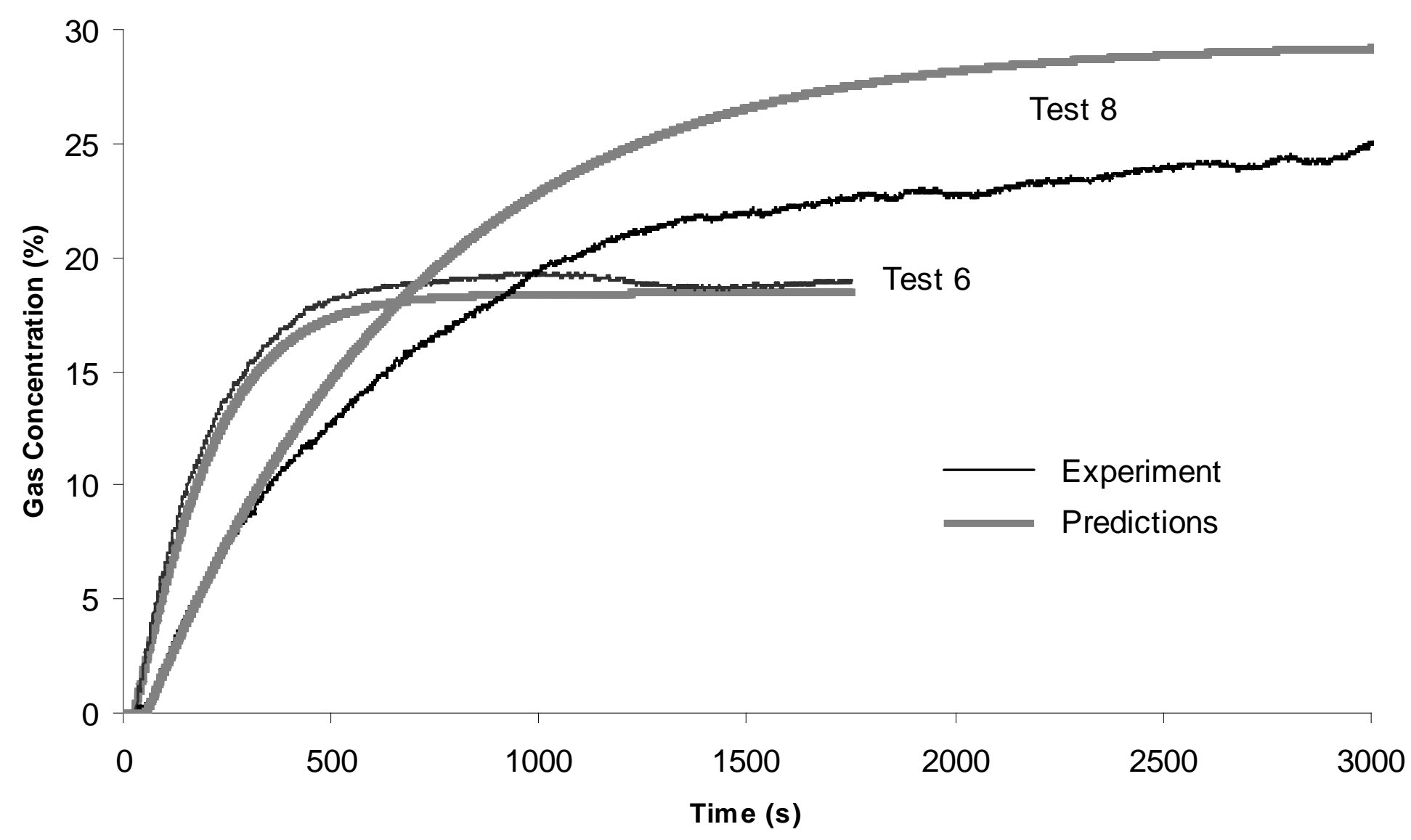

Figure 8. Gas concentration with time, Tests 6 and 8 


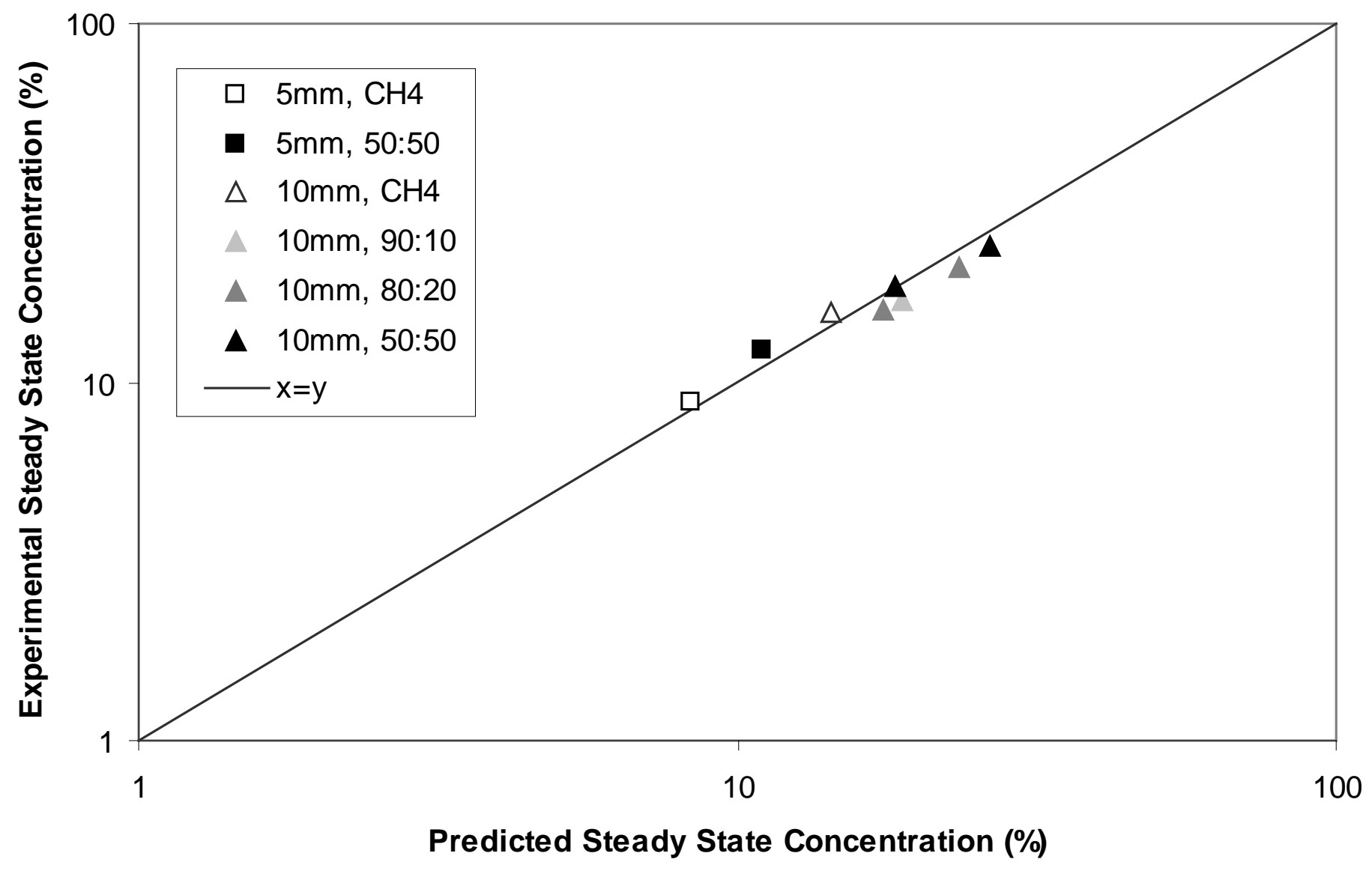

Figure 9. Steady state gas concentration for all tests 


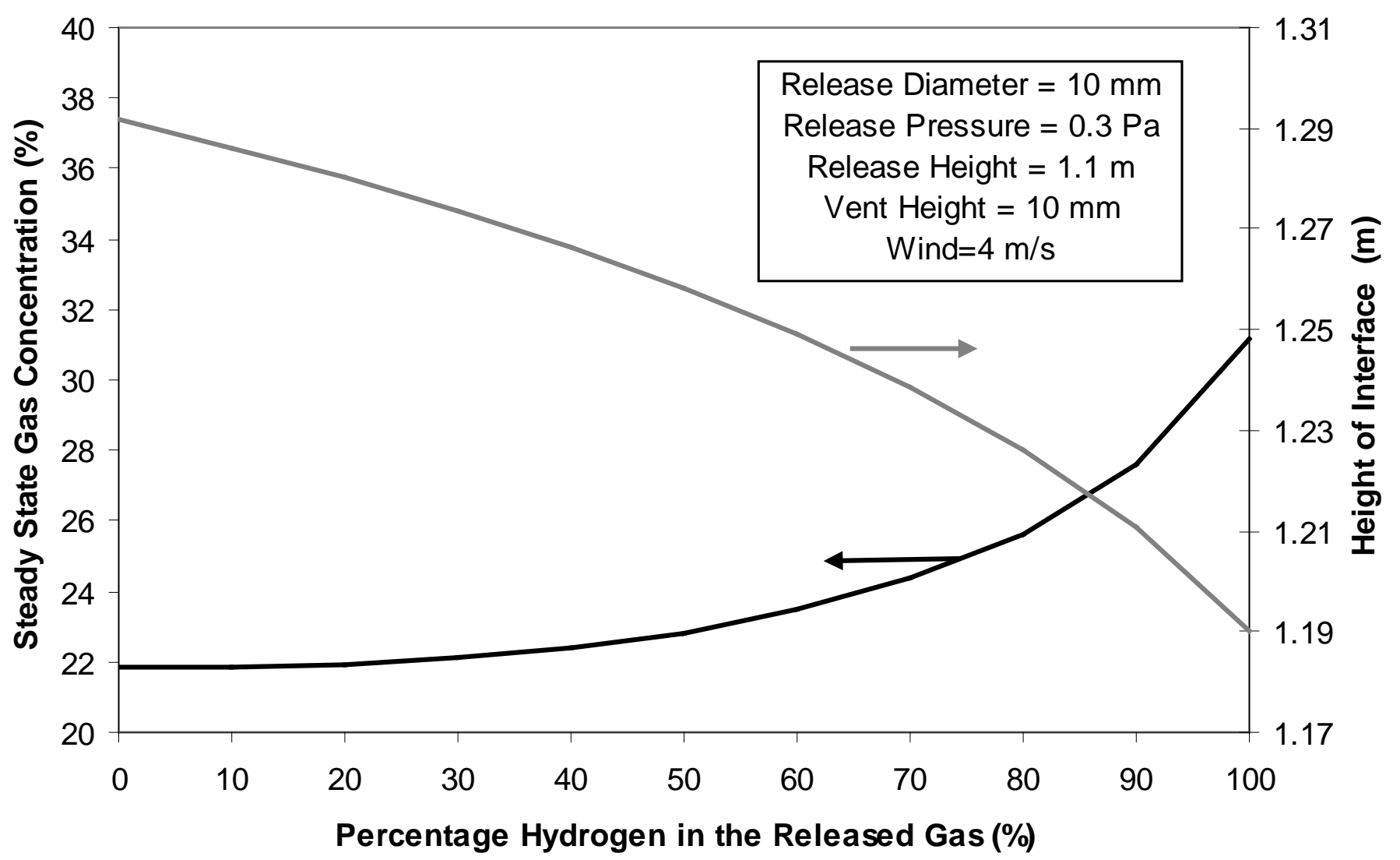

Figure 10. Steady state gas concentration and height of interface with amount of hydrogen in the released gas 
Table 1. Summary of experimental conditions

\begin{tabular}{|c|c|c|c|c|c|c|c|c|}
\hline Test & 1 & 2 & 3 & 4 & 5 & 6 & 7 & 8 \\
\hline Gas composition & $\mathrm{CH}_{4}$ & $50: 50$ & $\mathrm{CH}_{4}$ & $90: 10$ & $80: 20$ & 50:50 & $80: 20$ & $50: 50$ \\
\hline Release diameter (mm) & 5 & 5 & 10 & 10 & 10 & 10 & 10 & 10 \\
\hline Release height (m) & 1.1 & 1.1 & 1.1 & 1.1 & 1.1 & 1.1 & 0.1 & 0.1 \\
\hline Release gauge pressure (Pa) & $\begin{array}{c}0.20 \\
5\end{array}$ & 0.207 & $\begin{array}{c}0.30 \\
3\end{array}$ & 0.304 & 0.305 & 0.302 & 0.311 & 0.297 \\
\hline Height of vent opening (mm) & 10 & 15 & 50 & 15 & 10 & 50 & 20 & 15 \\
\hline
\end{tabular}


Table 2. Summary of gas layer formed at steady state.

\begin{tabular}{|c|c|c|c|c|c|c|c|c|}
\hline Test & 1 & 2 & 3 & 4 & 5 & 6 & 7 & 8 \\
\hline Gas composition & $\mathrm{CH}_{4}$ & $50: 50$ & $\mathrm{CH}_{4}$ & $90: 10$ & $80: 20$ & $50: 50$ & $80: 20$ & $50: 50$ \\
\hline Release diameter (mm) & 5 & 5 & 10 & 10 & 10 & 10 & 10 & 10 \\
\hline Calculated gas release rate $\left(\mathrm{m}^{3} \mathrm{~h}^{-1}\right)$ & 4.5 & 6.1 & 22.2 & 23.2 & 24.5 & 29.5 & 24.8 & 29.3 \\
\hline Release height (m) & 1.1 & 1.1 & 1.1 & 1.1 & 1.1 & 1.1 & 0.1 & 0.1 \\
\hline Height of interface (m) & 1.4 & 1.4 & 1.2 & 1.2 & 1.2 & 1.3 & 0.3 & 0.2 \\
\hline $\begin{array}{l}\text { Average gas concentration in layer } \\
\text { at steady state }(\% \mathrm{v} / \mathrm{v})\end{array}$ & 8.8 & 12.3 & 15.7 & 16.9 & 20.8 & 18.6 & 16.0 & 24.0 \\
\hline Wind speed at $10.75 \mathrm{~m}$ & 4.5 & 2.5 & 1.9 & 6.5 & 9.2 & 1.3 & 4.4 & 5.4 \\
\hline $\begin{array}{l}\text { Wind angle to inlet vent ( } 0 \text { degrees } \\
\text { is normal to vent) }\end{array}$ & 28 & 1 & 14 & 38 & 52 & 12 & 18 & 29 \\
\hline Ambient Temperature (C) & -2.4 & 0.8 & 1.9 & 2.7 & 2.5 & 1.9 & 6.8 & 5.5 \\
\hline
\end{tabular}

